Rev. Inst. Flor. v. 26 n. 2 p. 147-159 dez. 2014

http://dx.doi.org/10.4322/rif.2014.011

ISSN impresso 0103-2674/on-line 2178-5031

\title{
ASPECTOS AMBIENTAIS DA DISPOSIÇÃO DE RESÍDUOS SÓLIDOS EM ATERRO SANITÁRIO NA ZONA DE AMORTECIMENTO DAS UNIDADES DE CONSERVAÇÃO DO MUNICÍPIO DE ASSIS - SP ${ }^{1}$
}

\section{ENVIRONMENTAL ASPECTS OF SOLID WASTE DISPOSITION ON LANDFILL IN BUFFER ZONE OF PROTECTED AREAS OF ASSIS MUNICIPALITY - SP}

\author{
Regiane Novais LEITE ${ }^{2,3}$; Solange BONGIOVANNI²
}

\begin{abstract}
RESUMO - A análise dos aspectos ambientais da disposição de resíduos sólidos em aterro sanitário na zona de amortecimento das unidades de conservação Floresta Estadual e Estação Ecológica de Assis permitiu estimar impactos ambientais negativos, que podem afetar a biodiversidade e recursos naturais destas unidades. Pretendeu-se, através deste trabalho, alertar, por meio de relatório ambiental, o gestor municipal e os órgãos ambientais existentes em Assis sobre a situação dessa área, a fim de promover o encerramento das atividades do aterro e a destinação final correta dos resíduos sólidos gerados no município de Assis. A pesquisa pautou-se na legislação vigente e pertinente e nos métodos descritos pela literatura sobre aterramento de resíduos e impactos ambientais. Foram realizadas idas a campo para observação do cenário. Os aspectos ambientais analisados apresentaram correspondência com impactos ambientais negativos, os quais exibem potencial de causar ao ambiente: perda da qualidade e contaminação do solo, deterioração da qualidade das águas subterrâneas, deterioração da qualidade do ar, perda líquida dos habitats e alteração dos ecossistemas aquáticos e terrestres, e ao meio antrópico: impacto visual, sobre a saúde humana e socioambiental. Faz-se necessária a adoção de medidas mitigadoras, como a descontaminação dessa área após o encerramento do aterro, em prol do reestabelecimento da qualidade dessa paisagem e da minimização dos riscos à saúde pública.

Palavras-chave: Sistema Nacional de Unidades de Conservação da Natureza; Política Nacional de Resíduos Sólidos; impactos ambientais.
\end{abstract}

\begin{abstract}
The analysis of the environmental aspects of solid residue disposal in the landfill in buffer zone at the conservation units State Forest and Assis Ecological Station allows estimating negative environmental impacts, which may affect biodiversity and natural resources of these units. The purpose through this work was to alert, by environmental report, the municipal manager and others environmental agencies of Assis upon the situation of this area, promote the ending of the landfill and the correct disposal of solid waste generated in Assis municipality. The research is based on the actual relevant legislation and methods described in the literature about grounding waste and environmental impacts. Field visits were made to analyze the scenery. Environmental aspects analyzed, showed correspondence with negative environmental impacts, which exhibit potential to cause to the environment: loss of quality and contamination of the soil, deterioration of groundwater quality, deterioration of air quality, net loss of habitat and change aquatic and terrestrial ecosystem, and to the anthropic environment: visual impact on human health and socio-environmental. It is necessary to adopt mitigation instructions, such as decontamination of those areas after the shutdown of the landfill, in favor to reinstate the quality of this landscape and minimize risks to public health.
\end{abstract}

Keywords: National System of Nature Conservation; National Policy of Solid Waste; environmental impacts.

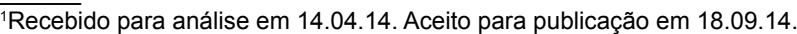

"Universidade Estadual Paulista "Júlio de Mesquita Filho", Faculdade de Ciências e Letras de Assis, Avenida Dom Antônio, 2100, Parque Universitário, 19806-900 Assis, SP, Brasil.

${ }^{3}$ Autor para correspondência: Regiane Novais Leite - regiane.novaisleite@gmail.com
} 


\section{INTRODUÇÃO}

A revolução industrial é tida como o marco inicial da crise ambiental, pois é a partir dela que o desenvolvimento econômico e demográfico se elevou, permitindo o aumento na produção dos bens de consumo e, consequentemente, na geração de resíduos. Ao mesmo tempo em que houve avanço tecnológico para expansão da produção industrial, houve também retrocesso ambiental, devido ao uso indiscriminado de recursos naturais, não se levando em conta a capacidade suporte do meio, provocando esgotamento de recursos que são essenciais ao ambiente ecologicamente equilibrado, promotor da qualidade de vida em todas as suas formas. Desse modo, tornou-se "cada vez mais significativa a ação humana, que ao se apropriar do território e de seus recursos naturais, causa grandes alterações na paisagem natural, com um ritmo muito mais intenso que aquele que normalmente a natureza imprime" (Ross, 1993, p. 64).

A disposição irregular e mal planejada de resíduos sólidos sobre o solo, sem o emprego de técnicas ambientalmente adequadas, pode causar diversos impactos negativos ao ambiente, tais como, a contaminação das águas superficiais e subterrâneas e do solo, a emissão de gases, a exalação de fortes odores, a proliferação de agentes causadores de doenças e a presença inadequada de coletores de materiais reutilizáveis e recicláveis (Neto et al., 2010). Uma das soluções para este problema é a deposição de resíduos sólidos em aterros sanitários.

Aterro sanitário é uma das técnicas de disposição final de resíduos sólidos, onde padrões aceitáveis quanto aos danos ambientais e à saúde pública são estabelecidos para sua operacionalização, consistindo no confinamento de resíduos sólidos na menor área e no menor volume possíveis, onde tais resíduos recebem uma camada de terra periodicamente, de forma a minimizar os impactos ambientais (Neto et al., 2010).

O tipo de aterro sanitário indicado para cada município é definido conforme a quantidade de resíduos gerada por sua população. No município de Assis, é utilizado o "Aterro Sanitário em Valas". $\mathrm{O}$ aterramento de resíduos em valas é recomendado para municípios de pequeno porte, onde a produção de lixo não ultrapasse $10(\mathrm{dez})$ toneladas por dia e deve possuir, basicamente, como infraestrutura operacional: cobertura diária dos resíduos, drenagens superficiais, controle de acesso (cerca de arame, cerca viva e guarita), controle de vetores, aceiro, limpeza da área, entre outros (Neto et al., 2010).

$\mathrm{O}$ aterramento irregular de resíduos sólidos é uma realidade de diversos municípios brasileiros, onde a gestão, em sua maioria, envolve apenas a coleta e a disposição final, sendo os procedimentos diferenciados (coleta seletiva, reciclagem, compostagem etc.) inexistentes ou ineficazes (Schalch et al., 2002). Para o mesmo autor, o gerenciamento inadequado de resíduos sólidos provoca desperdícios, além de ser fator importante para a manutenção das desigualdades sociais, consistindo em ameaça frequente à saúde pública. Outro ponto abordado é o agravamento da degradação ambiental ocasionado pelo gerenciamento inadequado dos resíduos, o que compromete a qualidade ambiental.

A zona de amortecimento das unidades de conservação Floresta Estadual e Estação Ecológica de Assis, com área de 20.483,2876 hectares, tem como finalidade minimizar os impactos advindos de sua vizinhança, com o propósito de proteger os ecossistemas naturais e o manancial de abastecimento da cidade de Assis (Represa Água do Cervo) localizado no interior destas unidades. A zona de amortecimento protege também os fragmentos florestais ali presentes que são importantes para manter a qualidade da paisagem, diminuir o isolamento e a descontinuidade entre as unidades de conservação, permitindo, assim, a existência de corredores ecológicos entre estas áreas. A zona de amortecimento abrange ainda sub-bacias hidrográficas tributárias da Bacia do Cervo (exceto as localizadas no perímetro urbano do município) e todas as microbacias hidrográficas que se delimitam com as unidades, desde os seus divisores de águas, sendo a conservação destes corpos d'água de fundamental importância por servirem de abastecimento ao município de Assis (Max et al., 2007a; Durigan et al., 2010).

O presente estudo teve como intuito a análise dos aspectos ambientais da disposição irregular e mal planejada de resíduos sólidos em aterro sanitário localizado na zona de amortecimento da Floresta Estadual e Estação Ecológica de Assis, que podem lhes causar impactos negativos, afetando sua biodiversidade e recursos naturais. Pretendeu-se, através deste trabalho, alertar, por meio de relatório ambiental, o gestor municipal e os órgãos 
ambientais existentes em Assis sobre a situação desta área, a fim de promover o encerramento das atividades do aterro e a destinação final correta dos resíduos sólidos gerados no município de Assis, buscando atender a proposta de gestão integrada de resíduos sólidos da Política Nacional de Resíduos Sólidos, pautada nos objetivos: "I - a prevenção e a precaução; II - o poluidor-pagador e o protetor-recebedor; III - a visão sistêmica, na gestão dos resíduos sólidos, que considere as variáveis ambiental, social, cultural, econômica, tecnológica e de saúde pública; IV - o desenvolvimento sustentável; $\mathrm{V}$ - a ecoeficiência, mediante a compatibilização entre o fornecimento, a preços competitivos, de bens e serviços qualificados que satisfaçam as necessidades humanas e tragam qualidade de vida e a redução do impacto ambiental e do consumo de recursos naturais a um nível, no mínimo, equivalente à capacidade de sustentação estimada do planeta; VI - a cooperação entre as diferentes esferas do poder público, o setor empresarial e demais segmentos da sociedade; VII - a responsabilidade compartilhada pelo ciclo de vida dos produtos; VIII - o reconhecimento do resíduo sólido reutilizável e reciclável como um bem econômico e de valor social, gerador de trabalho e renda e promotor de cidadania; IX $-\mathrm{O}$ respeito às diversidades locais e regionais; $\mathrm{X}-\mathrm{o}$ direito da sociedade à informação e ao controle social; XI - a razoabilidade e a proporcionalidade". (Brasil, 2010).

\section{MATERIAIS E MÉTODOS}

\subsection{Localização da Área}

A pesquisa foi realizada no município de Assis - São Paulo (Figura 1) e teve como área de análise o aterro sanitário em valas de Assis - Figura 2, estando este contido na zona de amortecimento da Floresta Estadual e da Estação Ecológica de Assis.

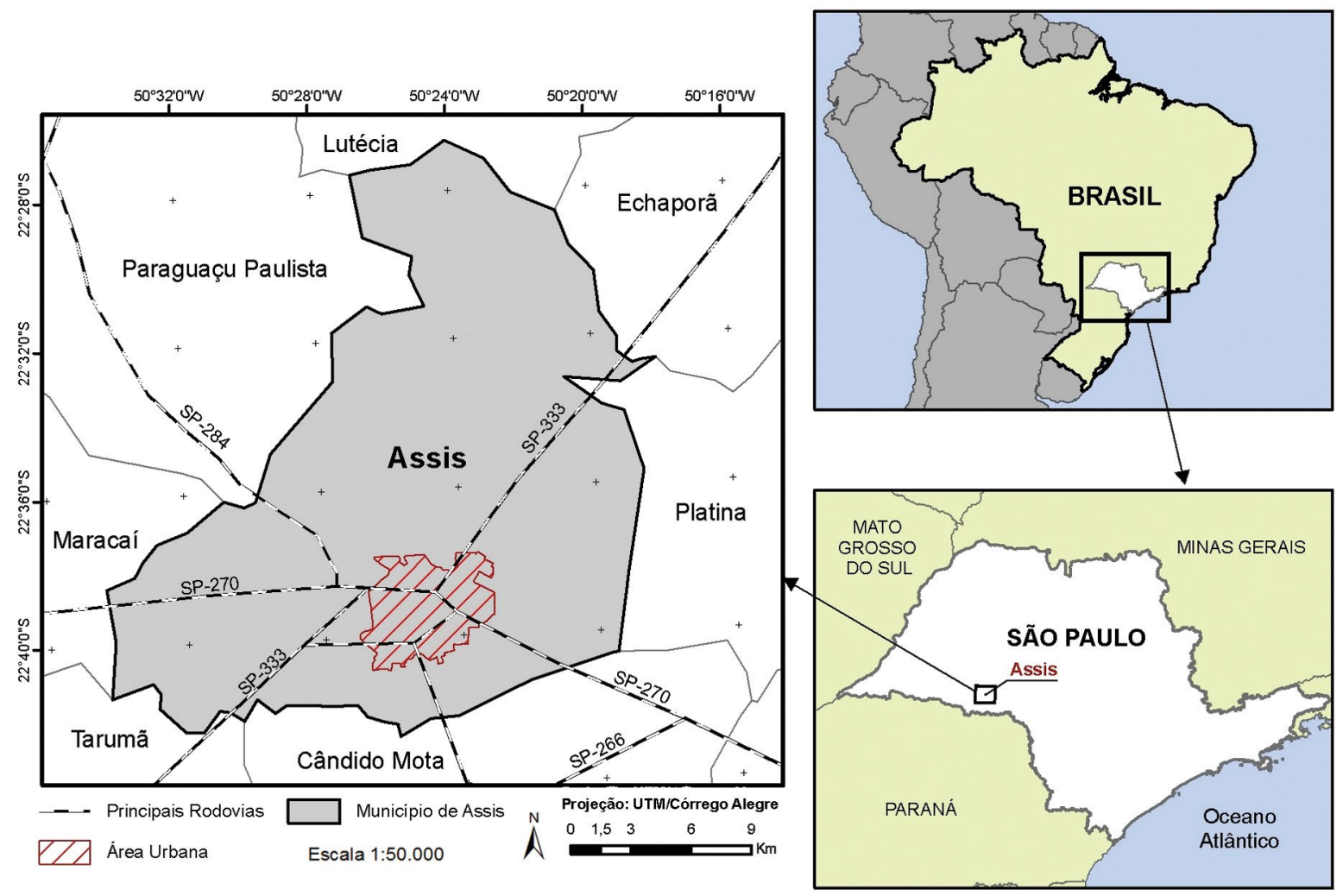

Figura 1. Localização do município de Assis - São Paulo (Fonte: Bongiovanni, 2008).

Figure 1. Assis municipality location - São Paulo (Source: Bongiovanni, 2008). 


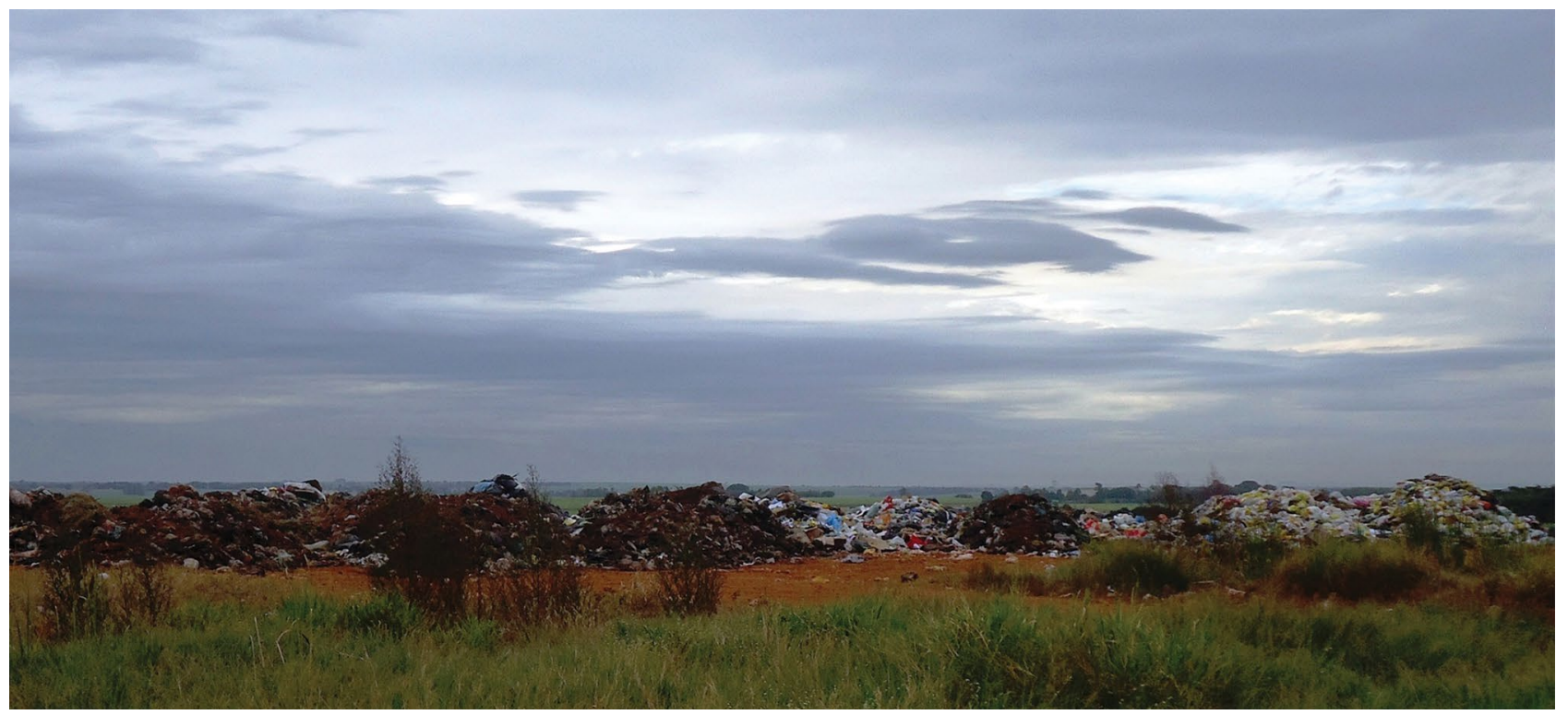

Figura 2. Aterro sanitário em valas de Assis - SP. Nota-se, na figura, resíduos sólidos produzidos no município de Assis e que em breve seriam aterrados.

Figure 2. Assis landfill ditches - SP. The figure shows solid waste produced in Assis municipality which were supposed to be buried soon.

O clima predominante no município de Assis é o tropical de altitude (Cwa) que, segundo a Classificação Climática de Köppen, é caracterizado por chuvas no verão e seca no inverno, com temperatura média máxima de $25{ }^{\circ} \mathrm{C}$ e média mínima de $18{ }^{\circ} \mathrm{C}$. A precipitação anual é de $1.441,5 \mathrm{~mm}$, tendo o mês mais seco precipitação de $45,8 \mathrm{~mm}$ e o mês mais úmido $214,2 \mathrm{~mm}$ de chuva. Assis está situada a uma altitude média de 560 metros, em relação ao nível do mar (Centro de Pesquisas Meteorológicas e Climáticas Aplicadas à Agricultura CEPAGRI, 2013).

A Estação Experimental de Assis tornou-se Floresta Estadual de Assis através do Decreto Estadual $\mathrm{n}^{\circ}$ 47.098, de 18/09/2002 (Max et al., 2007a). A Estação Ecológica de Assis foi criada pelo Decreto Estadual $n^{\circ} 35.697$, de 21/09/1992 e, posteriormente, ampliada por força do Decreto $\mathrm{n}^{\circ}$ 47.097, de 18/09/2002 (Durigan et al., 2010). As unidades de conservação contíguas de Assis (Figura 3), gestadas pelo Instituto Florestal, órgão da Secretaria Estadual de Meio Ambiente, possuem zona de amortecimento partilhada e representam uma importante área remanescente de conservação de Cerrado.
O aterro sanitário em valas de Assis, localizado na Estrada Municipal Assis - Lutécia (ASS-427) - Figura 3, foi implantado por meio da Licença de Instalação de número 11000811, de 28 de fevereiro de 2002, e começou a funcionar através da Licença de Operação de número 1100762, em 27 de fevereiro de 2003 (Companhia Ambiental do Estado de São Paulo - CETESB, 2013).

O "Mapa de solos do entorno da Estação Ecológica de Assis" do Plano para o Desenvolvimento Sustentável do Entorno da Estação Ecológica de Assis (Max et al., 2007b), indica que a unidade pedológica existente na área do aterro sanitário de Assis é o Latossolo Vermelho Distrófico Típico, Álico, A moderado, textura média (A arenoso). O trabalho desse mesmo autor apresenta, ainda, em "Mapa de hidrografia do entorno da Estação Ecológica de Assis", a Água Bonita (ou Água das Pontinhas) - tributária à Água das Antas, indicada na Figura 3, como corpo hídrico que irriga essa região. Não há corpos d'água superficiais perenes na área do aterro de Assis, existem apenas lagoas temporárias formadas em períodos de chuva. 


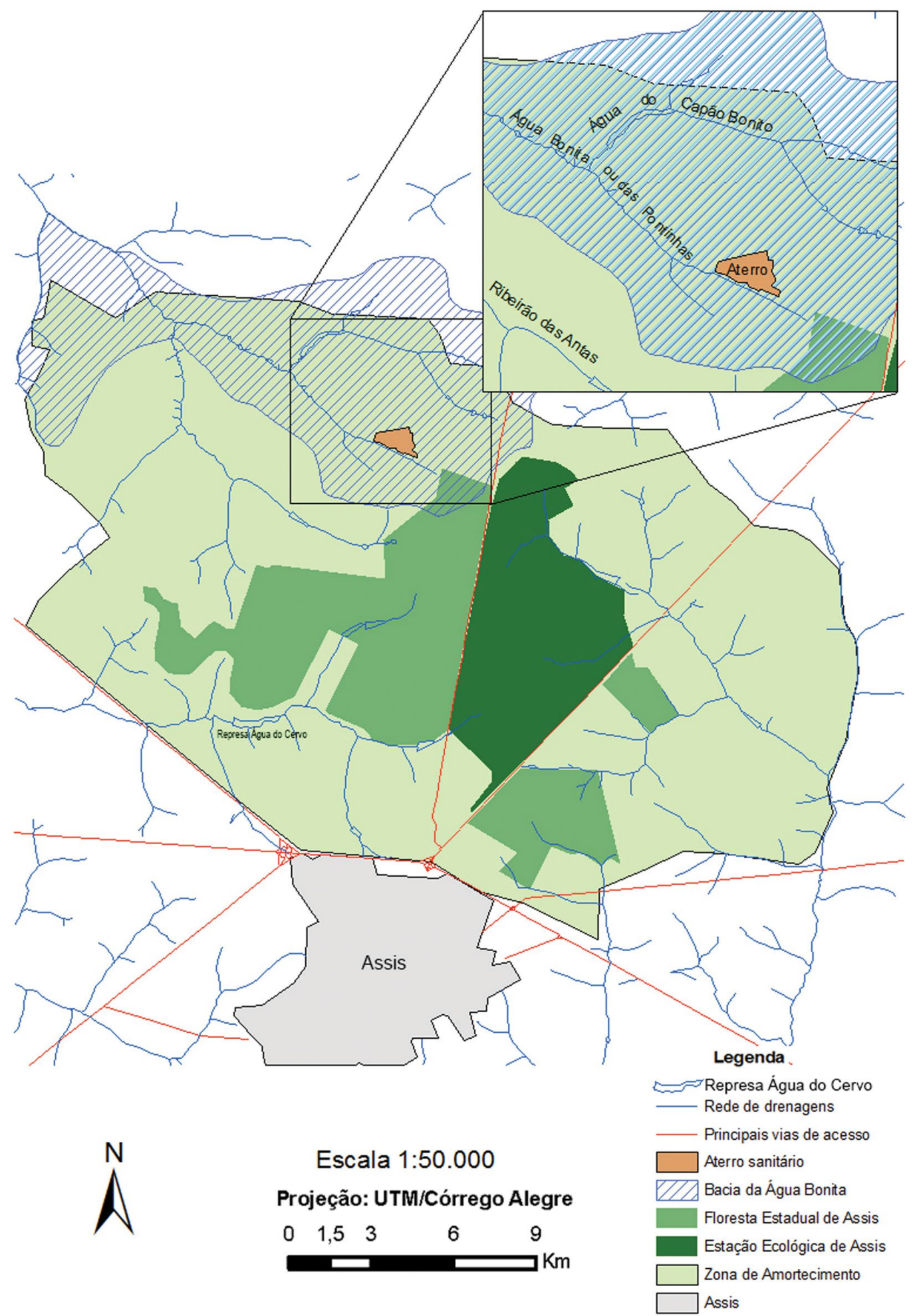

Figura 3. Mapa da região do aterro sanitário em valas de Assis. Visualiza-se na figura: as unidades de conservação e sua zona de amortecimento, o aterro sanitário (S 22³3’142 e O 50²4’456) e o corpo hídrico Água Bonita ou das Pontinhas (Fonte: Max et al., 2007b - adaptado por Gustavo Reis de Brito, 2014).

Figure 3. Map of Assis landfill ditches region. The figure indicates: conservation areas and its buffer zone, the landfill (S $22^{\circ} 33^{\prime} 142$ and W 50 $24^{\prime} 456$ ) and the water body Água Bonita or Pontinhas (Source: Max et al., 2007b - adapted by Gustavo Reis de Brito, 2014). 


\subsection{Metodologia Aplicada}

A pesquisa teve como base a legislação pertinente e vigente, Lei $\mathrm{n}^{0}$ 9.985/00, que criou o Sistema Nacional de Unidades de Conservação (Brasil, 2000), e Lei $n^{\circ} 12.305 / 10$, que instituiu a Política Nacional de Resíduos Sólidos (Brasil, 2010), e para a análise foi utilizada uma Matriz de Identificação, por se tratar de uma ferramenta de uso comum e simples em estudos ambientais, objetivando identificar as prováveis interações entre os componentes da atividade e os elementos do meio, sendo esta metodologia indicada por Sánchez (2008).

De forma adaptada, foi empregada a "Matriz de identificação de aspectos e impactos ambientais" de Sánchez e Hacking (2002), em que aspectos ambientais do aterramento de resíduos sólidos foram correlacionados com impactos ambientais desta atividade (Quadro 1). Foram realizadas inspeções de campo para o preenchimento de uma lista de verificação ("Checklist"), a qual foi transposta para a matriz de identificação em questão.

Quadro 1. Matriz de identificação de aspectos e impactos ambientais para aterro sanitário em valas.

Table 1. Matrix identification of environmental aspects and impacts to landfill ditches.

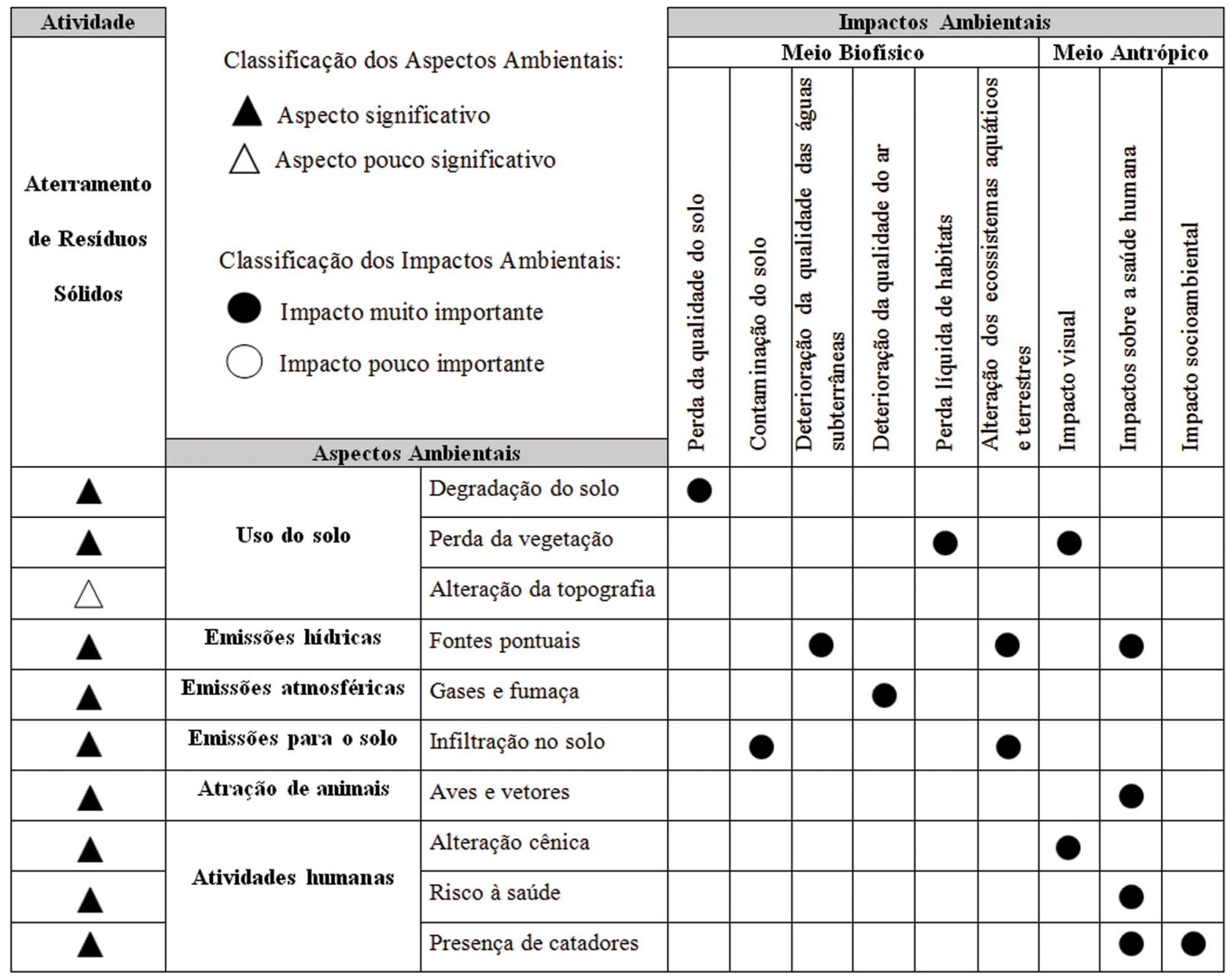

Fonte: Sánchez e Hacking, 2002 - adaptado.

Source: Sánchez \& Hacking, 2002 - adapted. 


\section{RESULTADOS E DISCUSSÃO}

O emprego da "Matriz de identificação de aspectos e impactos ambientais para aterro sanitário em valas" teve como intuito correlacionar os aspectos ambientais do aterramento de resíduos sólidos com os impactos desta atividade. Desse modo, aspectos ambientais sobre a disposição de resíduos sobre o solo na zona de amortecimento das unidades de conservação de Assis permitiram estimar os impactos ambientais desta operação.

Conforme a matriz de identificação, os aspectos ambientais sobre o "uso do solo" são correspondentes à alteração do ambiente natural da zona de amortecimento para a implantação do aterro sanitário em valas de Assis, causando: degradação do solo, perda da vegetação e restrições de uso como aspectos "significativos", e alteração da topografia como aspecto "pouco significativo". Os aspectos ambientais sobre o uso do solo, exceto alteração da topografia, apresentaram correlação com impactos ambientais de nível "muito importante", em face ao potencial de alterarem a qualidade ambiental.
A deposição de resíduos sólidos em valas, sem mantas de polietileno de alta de densidade - PEAD, como é o caso do aterro de Assis, permite o contato direto entre o líquido percolado (chorume) e o solo, tornando-o inviável para a agropecuária ou para demais atividades que apresentem utilização intensa do solo, já que há perda de sua qualidade. Para a instalação do aterro de Assis, a vegetação original desta área foi retirada, deixando o solo exposto e desprotegido, extinguindo abrigos e refúgios da vida silvestre, causando a perda líquida de habitats e impacto visual, formando um descontínuo entre o ambiente natural e o antrópico. A alteração da topografia não foi significativa, pois as valas são totalmente preenchidas com resíduos e terra, não havendo elevação ou decaimento topográfico significativo por longo tempo, embora nas duas primeiras inspeções de campo tenham sido observados morros de resíduos aguardando o aterramento, esta situação não foi vista nas demais vistorias. Em maio de 2013, uma nova vala foi aberta (Figura 4) e, aparentemente, esta vala recebeu uma camada de solo argiloso, o que dificulta a infiltração de chorume, mas ainda assim o aterro opera em inconformidade.

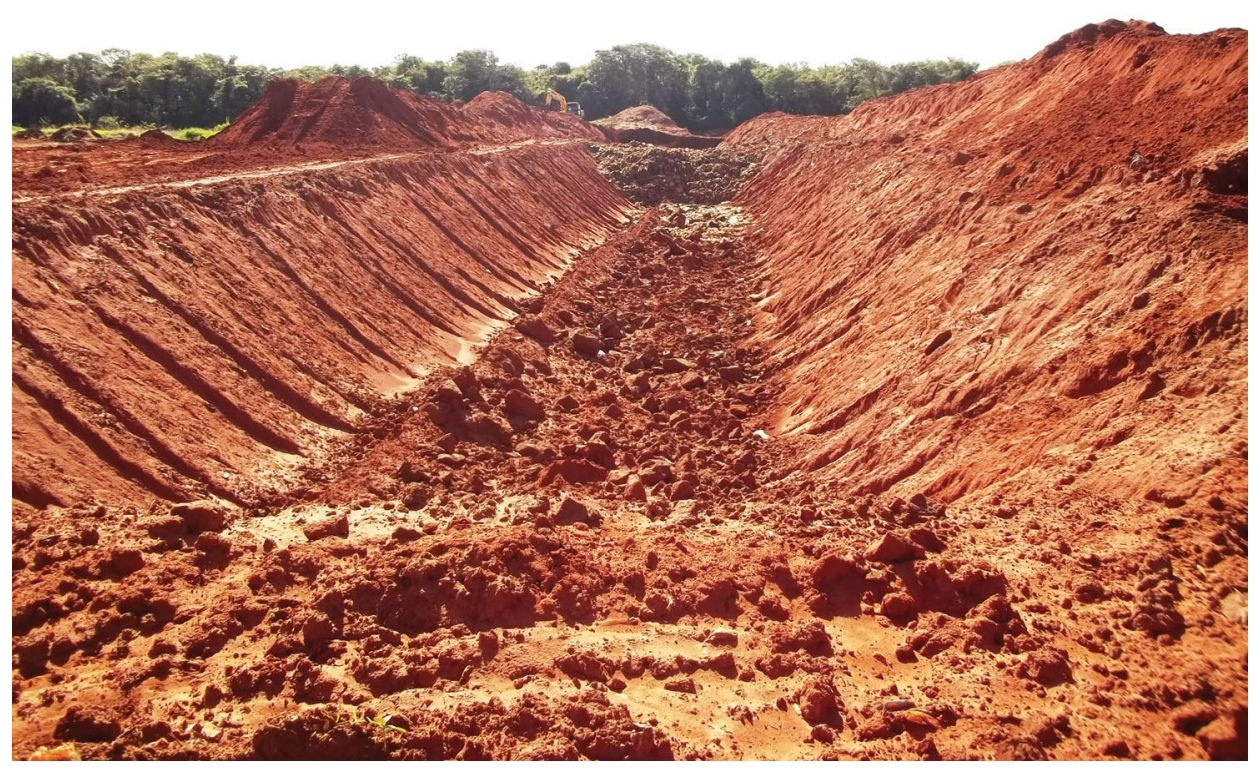

Figura 4. Nova vala no aterro sanitário de Assis - SP, instalada em maio de 2013. Observa-se, na figura, uma camada de solo argiloso sobre a base da vala.

Figure 4. New ditch in Assis landfill - SP, installed in May 2013. It can be observed by the figure that there is a layer of clay soil on the base of the ditch. 
O aspecto ambiental "emissões hídricas" corresponde à formação de chorume (líquido escuro, ácido e de odor desagradável, resultante de atividade enzimática extracelular de bactérias anaeróbicas para a decomposição de resíduos sólidos), caracterizado como uma fonte poluidora pontual que percola e atinge as águas subterrâneas, classificando-se como aspecto ambiental "significativo". Em períodos de chuva, infiltrações de água nos depósitos em aterros são facilitadas, carreando consigo substâncias inorgânicas, como carbonatos, sulfatos, nitratos e cloretos. Há também infiltração de íons magnésio, sódio, potássio, cálcio e amônio, e de íons de metais pesados (Schalch et al., 2002).

A demanda bioquímica de oxigênio - DBO em águas que sofrem infiltração oriunda de depósitos de aterros sanitários varia conforme o tempo de deposição da matéria orgânica. Depósitos mais antigos apresentam variação de 200 a $2.000 \mathrm{mg} / \mathrm{L}$ e os depósitos mais recentes possuem valores superiores a $20.000 \mathrm{mg} / \mathrm{L}$. A contaminação destas águas está relacionada com a profundidade e direção do lençol freático, a força de adsorção e a capacidade de autodepuração do solo onde há percolação do chorume, tendo a natureza do solo influência direta sobre a velocidade de escoamento das águas infiltradas. Essas características são de grande importância e resultam em infiltrações que podem comprometer as águas subterrâneas imediatamente ou após alguns decênios, sendo a capacidade de autodepuração do solo direcionadora desse processo (Schalch et al., 2002).

Desse modo, a deposição de resíduos no solo arenoso do aterro de Assis facilita a infiltração de chorume da decomposição destes resíduos, podendo levar à contaminação das águas subterrâneas que apresentam ligação com sub-bacias que abastecem a Represa Água do Cervo, manancial de abastecimento da cidade de Assis. A deterioração da qualidade das águas subterrâneas, a alteração dos ecossistemas aquáticos e o impacto sobre a saúde humana são considerados como impactos de nível "muito importante" pelo passivo ambiental à saúde pública e aos ecossistemas aquáticos, em especial por ser um risco à Represa Água do Cervo.

O aspecto ambiental "emissões atmosféricas" está condicionado à decomposição da matéria orgânica e à falta de revolvimento dos resíduos dispostos no solo, que acelera o consumo de oxigênio por bactérias aeróbicas, tornando baixa a disponibilidade de oxigênio e facilitando a ação de bactérias anaeróbicas que, através de seu metabolismo, liberam gases, como metano $\left(\mathrm{CH}_{4}\right)$ e dióxido de carbono $\left(\mathrm{CO}_{2}\right)$, emitidos em grandes quantidades, além da liberação de outros gases (Schalch et al., 2002).

A decomposição da matéria orgânica em aterros é dividida em duas fases (Filho e Mahler, 2005): Acidogênica - corresponde à formação de ácidos, tais como, o ácido acético e o ácido propiônico, que são hidrolisados e produzem ácidos graxos, açúcares simples, aminoácidos e outros compostos orgânicos de baixo peso molecular que são empregados na fase seguinte; Metanogênica diz respeito à síntese de metano e de dióxido de carbono a partir de ácidos formados na fase anterior, através da atuação de microrganismos específicos, como fungos e bactérias. Durante esse processo, outros gases, como o sulfeto de hidrogênio $\left(\mathrm{H}_{2} \mathrm{~S}\right)$, o nitrogênio $\left(\mathrm{N}_{2}\right)$ e o hidrogênio $\left(\mathrm{H}_{2}\right)$ são formados. Há também a queima dos resíduos devido à propriedade de combustão de alguns materiais, liberando fumaças com altos teores de dióxido de carbono.

Gases liberados por meio de decomposição da matéria orgânica e por queima de resíduos sólidos são poluentes e contribuem para o agravamento do efeito estufa, em especial o metano, que apresenta 21 vezes maior capacidade de causar danos ao ambiente, quando comparado ao dióxido de carbono. A dimensão da área atingida por esse aspecto ambiental é imensurável, por se tratar de meio atmosférico, podendo atingir grandes áreas, classificando-se como "significativo". Desse modo, a deterioração da qualidade do ar é um impacto de nível "muito importante" por conta da sua magnitude.

O aspecto ambiental "emissões para o solo" relaciona-se com a decomposição da matéria orgânica, sendo ela um dos constituintes do chorume e de grande importância para a complexação e o transporte de metais pesados, além da retenção de alguns contaminantes orgânicos. A matéria orgânica natural do solo altera a quantidade de matéria orgânica presente no chorume que fica em solução no solo, alterando, por consequência, os teores de matéria orgânica nas águas. 
A matéria orgânica contida no solo apresenta-se, em maior proporção, no horizonte superficial, de modo que infiltrações de chorume tendem a alterar a quantidade de matéria orgânica nos horizontes mais profundos, sendo um indício da transição da pluma de contaminação para determinadas profundidades (Leite et al., 2004).

As infiltrações no solo são consideradas como aspecto ambiental "significativo" porque o chorume altera suas propriedades físicas, químicas e biológicas, fazendo com que haja perda de suas características, representando um risco ambiental aos ecossistemas terrestres. Sendo assim, a contaminação do solo e a alteração dos ecossistemas terrestres são impactos classificados como "muito importante", devido ao dano que causam ao ambiente

O aspecto ambiental "atração de animais", classificado como "significativo", ocorre pela oferta de alimento, ocasionada por falta de recobrimento com terra dos resíduos depositados no solo, atraindo aves (urubus, em sua maioria) e vetores, tais como, moscas, mosquitos, ratos, baratas, e outros animais das unidades de conservação e da região de entorno.
A proximidade com as unidades de conservação, em especial com a Estação Ecológica de Assis, e com os corredores ecológicos que ligam as unidades à zona de amortecimento, possibilita a atração de diversos animais, aves, em sua maioria. Foram avistados urubus, Figura 5, que são comuns em locais onde há matéria orgânica em decomposição. Ressalta-se, ainda, a possibilidade de migração dos animais que vivem no aterro para às unidades de conservação e vice-versa.

As modificações do ambiente natural para o aterramento de resíduos alteraram a qualidade da paisagem, permitindo a propagação de vetores e de microrganismos patogênicos que apresentam potencial de afetar a saúde da população rural vizinha, já que o aterro pode ser uma área para o desenvolvimento de epidemias. A atividade de aterramento de resíduos causa impactos de nível "muito importante", como os impactos sobre a saúde humana, pois atrai vetores de diversas doenças. A atração de aves e vetores pode ainda causar desequilíbrios ecológicos tanto na área do aterro quanto às unidades de conservação, já que há possibilidade de migrações.

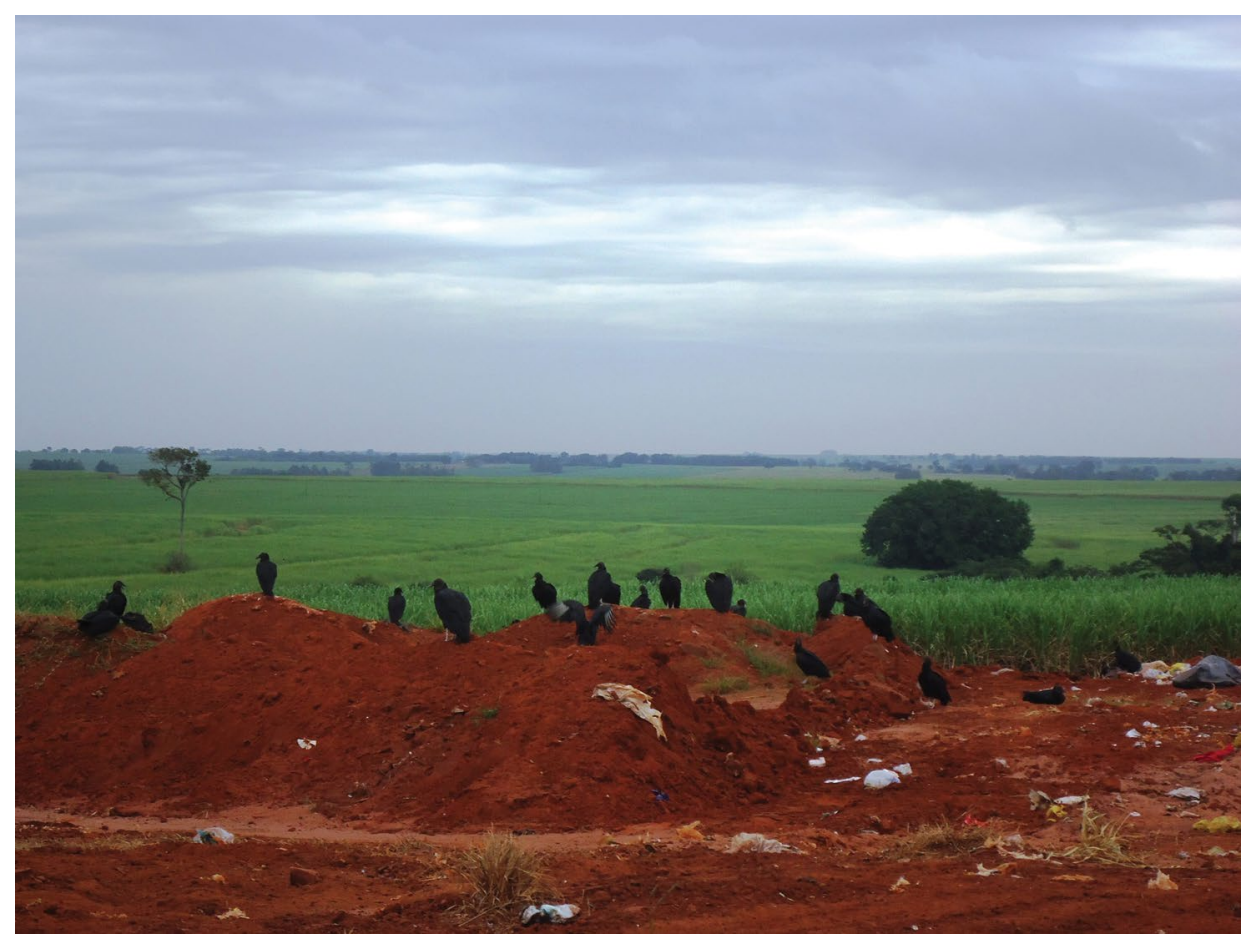

Figura 5. Urubus no aterro sanitário em valas de Assis - SP. Esta atração de aves deve-se à matéria orgânica em decomposição e à falta de recobrimento dos resíduos com terra.

Figure 5. Vultures in Assis landfill ditches - SP. Birds are attracted due to decaying organic matter and lack of covering waste with earth. 
O aspecto ambiental "atividades humanas", classificado como "significativo", corresponde à alteração cênica, ao risco à saúde e à presença de catadores. Tais aspectos ocorrem pela utilização dessa área para o aterramento de resíduos, onde o cenário natural foi transformado (antropizado) e tornou-se um local para o desenvolvimento de um trabalho informal - a catação de materiais reutilizáveis e recicláveis - por não ter vínculo com a Prefeitura, cooperativas e afins.

A alteração cênica é pronunciada nessa região, formando um descontínuo com o ambiente natural da zona de amortecimento e das unidades de conservação. A falta de controle do acesso ao aterro, principalmente sobre a entrada $\mathrm{e}$ permanência de pessoas que não são funcionários, é o principal fator que permite o desenvolvimento da catação de resíduos. Verificou-se essa situação em ida ao aterro, onde foi possível observar que os catadores revolviam o lixo sem o uso de equipamentos de proteção individual - EPI, como luvas de raspa de couro, botinas, bonés ou demais trajes e acessórios que conferem proteção física, consistindo em risco à saúde. Esses catadores estavam lá de maneira ilegal, já que a entrada de pessoas não autorizadas é proibida (expressa em placa de aviso na entrada do aterro), porém não havia guarda ou qualquer outro funcionário na guarita. Essa condição de ocupação está relacionada à baixa renda e à baixa oferta de empregos.

O aterro sanitário em valas de Assis e a presença de catadores caracterizam-se como impactos de nível "muito importante". O primeiro relaciona-se com o impacto visual, pois houve alteração do cenário, e o segundo está vinculado aos impactos sobre a saúde humana e socioambiental, em que catadores trabalham em condições precárias, expostos às doenças e demais mazelas.

O Plano Diretor do Município de Assis, instituído pela Lei Complementar $n^{\circ} 10$, de 10 de outubro de 2006, apresenta como metas, em seu Art. 23, inciso XI: "promover a instalação de novo Aterro Sanitário Municipal, somente, quando restarem esgotadas todas as possibilidades de utilização do atual Aterro, em local fora da Zona de Amortecimento da Estação Ecológica de Assis." e inciso XII: “planejar a localização de novo Aterro Sanitário Municipal de modo a não comprometer a integridade de recursos naturais, as bacias e mananciais de abastecimento público de água, as reservas e as áreas florestais, as áreas de proteção ambiental e as de preservação permanente.”, e em seu Art. 65, $\S 2^{\circ}$ : "O atual Aterro Sanitário Municipal, localizado no interior da Zona de Amortecimento da Estação Ecológica de Assis, terá seu funcionamento encerrado assim que se esgotarem as possibilidades de sua utilização, implementando, assim, processo de recuperação ambiental." (Assis, 2006).

Os problemas ambientais ocorridos na zona de amortecimento das unidades de conservação de Assis são reflexos da ineficiência na delimitação e proteção das áreas de interesse ambiental. A implantação de um novo aterro sanitário em outro local não é possível, visto que não há áreas livres no município de Assis, restando apenas as que se limitam com o aeroporto e que não poderiam ser utilizadas por conta da atração de aves que um aterro sanitário causa, afetando o tráfego aéreo e provocando acidentes à avifauna, de modo que a Lei $\mathrm{n}^{\mathrm{o}} 12.725 / 12$ define como área de segurança aeroportuária um raio de $20 \mathrm{~km}$ a partir do centro geométrico da maior pista do aeródromo (Brasil, 2012).

Max et al. (2007a), no Plano de Manejo da Floresta Estadual de Assis, e Durigan et al. (2010), no Plano de Manejo da Estação Ecológica de Assis, apresentam o aterro sanitário da Prefeitura Municipal de Assis como uma fonte de riscos para o equilíbrio do ecossistema destas unidades de conservação, devido à proximidade em que ele se encontra destas áreas.

Max et al. (2007b) indicam que, no Plano para o Desenvolvimento Sustentável do Entorno da Estação Ecológica de Assis, a população faz revindicações quanto à fiscalização dos problemas ambientais nas áreas das unidades de conservação (incluindo a sua zona de amortecimento). Entre essas cobranças, o controle e fiscalização do aterro sanitário foi um dos pedidos, ressaltando o dano que esta atividade pode causar. Ainda nesse Plano, foi tratado que o aterro sanitário apresenta potencial de gerar problemas à área de expansão da Estação Ecológica de Assis, limitando o crescimento desta unidade, 
sendo este fator condicionado à forma de manejo e extensão do aterro. Discorre também, sobre o aterro ser um risco à qualidade da água que abastece diversas propriedades a jusante.

Vitalli (2007) aponta que o aterro sanitário de Assis teve como motivo de criação o recebimento do material excedente da Usina de Compostagem de Assis, sendo destinados a este aterro todos os resíduos coletados no município de Assis, não operando, então, de acordo com as normas e regulamentos impostos para legalização desta atividade. A autora destaca, ainda, a quantidade de resíduos (cerca de 60 (sessenta) toneladas por dia) acima do limite permitido que é destinada ao aterro e a falta de infraestrutura operacional.

A Companhia Ambiental do Estado de São Paulo - CETESB renovou a Licença de Operação do aterro sanitário de Assis sob o número 59000508 para a atividade: Aterro Sanitário para Rejeitos da Usina de Compostagem de Assis, na data de 01 de fevereiro de 2012, com vencimento previsto para 01 de fevereiro de 2013. Foi solicitada Licença Prévia e esta não foi cedida, estando arquivada desde 18 de julho de 2012 (CETESB, 2013).

$\mathrm{O}$ aterro continua operando, apesar da licença ambiental vencida, e recebendo resíduos que não são compatíveis aos resíduos que deveria receber (rejeitos da Usina de Compostagem) e em quantidades que extrapolam a capacidade indicada para o aterramento em valas, além de apresentar infraestrutura precária. Por esses motivos, o aterro sanitário de Assis obteve pontuação de 4,5, enquadrando-se como I (Condições Inadequadas) no Inventário Estadual de Resíduos Sólidos 2013 (publicação mais recente deste relatório), no qual consta também que o aterro não possui as Licenças de Instalação e de Operação e que está cumprindo Termo de Ajustamento de Conduta - TAC (Iwai et al., 2014). Este fato pode ser considerado um avanço na fiscalização ambiental, visto que no Inventário Estadual de Resíduos Sólidos 2012 o aterro de Assis se enquadrava como A (Condições Adequadas), obtinha pontuação de 7,2 e possuía tais licenças para sua operação (Iwai et al., 2013).

\section{CONCLUSÕES}

Através dos aspectos ambientais analisados para estimação de impactos ambientais, foi possível inferir que a operação de um aterro sanitário na zona de amortecimento das unidades de conservação de Assis representa riscos de impactos ambientais negativos à biodiversidade e aos recursos naturais destas unidades (e de sua zona de amortecimento), em especial ao abastecimento de água para propriedades rurais a jusante e à Represa Água do Cervo. Como instituído pelo Sistema Nacional de Unidades de Conservação (Lei $n^{\circ}$ 9.985/00), operações desse tipo não são permitidas em zona de amortecimento, mas mesmo assim o aterro foi implantado, sendo que essa Lei Federal já estava em vigor. As atividades potencialmente impactantes constam nos Planos de Manejo das duas unidades, pois esta é uma responsabilidade de suas gestões, mas elas por si só não têm força para promover o encerramento do aterro.

Faz-se necessário o encerramento desse aterro, visto que seu prazo para finalização de atividades está vencido, bem como a mitigação dos impactos ambientais causados na área do aterro e possivelmente às unidades de conservação, de modo a atender uma das exigências, a de descontaminação de áreas impactadas por deposição de resíduos sólidos, da Política Nacional de Resíduos Sólidos (Lei $\mathrm{n}^{\circ}$ 12.305/10). Dessa maneira, procura-se reestabelecer a qualidade da paisagem e prover o devido funcionamento da zona de amortecimento, protegendo a Floresta Estadual e Estação Ecológica de Assis e minimizando os riscos à saúde da população local.

Para que esse cenário seja alterado, devem-se modificar os processos produtivos e incentivar a mudança ambiental nos hábitos de consumo, por meio de Educação Ambiental e estímulos fiscais, visando minimizar a quantidade de resíduos sólidos gerada, além da implantação de uma gestão integrada destes resíduos, priorizando os procedimentos diferenciados, como coleta seletiva, reciclagem e compostagem, de modo que seja destinado ao aterro apenas o rejeito (resíduos que não apresentam possibilidade de reutilização e/ou reciclagem/compostagem), promovendo o menor uso dos recursos naturais e a geração de empregos para cooperativas e afins. 
A gestão de resíduos sólidos é um desafio à sociedade moderna, mas é extremamente necessária para a manutenção de um ambiente sadio, promotor da qualidade de vida.

\section{REFERÊNCIAS BIBLIOGRÁFICAS}

ASSIS. Lei Complementar $n^{\circ} 10$, de 10 de outubro de 2006. Disponível em: <http://www.assis.sp.leg. $\mathrm{br} /$ leis/codigos-e-estatutos/lc\%20010-06.pdf $>$. Acesso em: 26 jun. 2013.

BONGIOVANNI, S. Caracterização geológica do município de Assis: a importância do estudo das coberturas cenozóicas. 2008. 218 f. Tese (Doutorado em Geologia Regional) - Instituto de Geociências e Ciências Exatas, Universidade Estadual Paulista, Rio Claro.

BRASIL. Lei $\mathrm{n}^{\circ}$ 9.985, de 18 de julho de 2000. Institui o Sistema Nacional de Unidades de Conservação. Disponível em: <http://www.planalto. gov.br/ccivil_03/leis/19985.htm>. Acesso em: 17 nov. 2012.

Lei $\mathrm{n}^{\mathrm{o}}$ 12.305, de 2 de agosto de 2010. Institui a Política Nacional de Resíduos Sólidos. Disponível em: <http://www.planalto.gov.br/ ccivil_03/_ato2007-2010/2010/1ei/112305.htm>. Acesso em: 15 abr. 2013.

. Lei $\mathrm{n}^{\circ} 12.725$, de 16 de outubro de 2012. Disponível em: <http://www.planalto.gov.br/ ccivil_03/Ato2011-2014/2012/Lei/L12725.htm>. Acesso em: 15 out. 2013.

CENTRO DE PESQUISAS METEOROLÓGICAS E CLIMÁTICAS APLICADAS À AGRICULTURA CEPAGRI. Clima dos municípios paulistas. Disponível em: <http://www.cpa.unicamp.br/ outras-informacoes/clima-dos-municipiospaulistas.html>. Acesso em: 21 jul. 2013.

COMPANHIA AMBIENTAL DO ESTADO DE SÃO PAULO - CETESB. Licenciamento ambiental. Disponível em: <http://www.cetesb.sp.gov.br/ licenciamento/licenciamento-ambiental/1-paginainicial>. Acesso em: 22 jun. 2013.
DURIGAN, G. et al. Plano de manejo da Estação Ecológica de Assis. Assis: Instituto Florestal, 2010. $171 \mathrm{p}$.

FILHO, L.F.B.; MAHLER, C.F. Estudo de gases em aterros de resíduos sólidos urbanos. 2005. 218 f. Dissertação (Mestrado em Engenharia Civil) - Universidade Federal do Rio de Janeiro, Rio de Janeiro.

IWAI, C.K. et al. Inventário estadual de resíduos sólidos urbanos 2012. São Paulo: Companhia Ambiental do Estado de São Paulo - CETESB, 2013. p. 96.

et al. Inventário estadual de resíduos sólidos urbanos 2013. São Paulo: Companhia Ambiental do Estado de São Paulo - CETESB, 2014. p. 100.

LEITE, C.M.B.; BERNARDES, R.S.; OLIVEIRA, A. Método Walkley-Black na determinação da matéria orgânica em solos contaminados por chorume. Revista de Engenharia Agrícola e Ambiental, v. 8, n. 1, p. 111-115, 2004.

MAX, J.C.M. et al. Plano de manejo da Floresta Estadual de Assis. IF Série Registros, n. 30, p. 1-80, 2007a.

MAX, J.C.M. et al. Plano para o desenvolvimento sustentável do entorno da Estação Ecológica de Assis. IF Série Registros, n. 32, p. 1-48, 2007 b.

NETO, A.S. et al. Manual de operação de aterro sanitário em valas. São Paulo: Companhia Ambiental do Estado de São Paulo - CETESB, 2010. 24 p.

ROSS, J.L.S. Análise empírica da fragilidade dos ambientes naturais e antropizados. Revista do Departamento de Geografia da FFLCH/USP, n. 8, p. 1-13, 1993.

SÁNCHEZ, L.H. Avaliação de impacto ambiental: conceitos e métodos. São Paulo: Oficina de Textos, $2008.595 \mathrm{p}$

; HACKING, T. An approach to linking environmental impact assessment and environmental management systems. Impact Assessment and Project Appraisal, v. 20, n. 1, p. 25-38, 2002. 
LEITE, R.N.; BONGIOVANNI, S. Aterro sanitário em zona de amortecimento

SCHALCH, V. et al. Gestão e gerenciamento de resíduos sólidos. São Carlos: Universidade de São Paulo, Escola de Engenharia de São Carlos: Departamento de Hidráulica e Saneamento, 2002.

$97 \mathrm{p}$.

VITALLI, P.D.L. Análise dos aspectos jurídicos correlatos à zona de amortecimento de unidades de conservação: estudo de caso da Estação Ecológica de Assis (SP), 2007. 148 f. Dissertação (Mestrado em Ciências da Engenharia Ambiental) - Escola de Engenharia de São Carlos, Universidade de São Paulo, São Carlos. 